\title{
NOTAS EXPLORATÓRIAS SOBRE A MÍDIA CINEMÁTICA NO ENSINO DE HISTÓRIA NA CIDADE DO RIO GRANDE/RS
}

\author{
EXPLORATORY NOTES ON THE KINEMATIC MEDIA IN THE TEACHING OF HISTORY \\ IN THE CITY OF RIO GRANDE/RS
}

Luiz Paulo da Silva Soares ${ }^{1}$

\begin{abstract}
RESUMO: O presente trabalho, visa apresentar algumas notas exploratórias sobre a dissertação de Mestrado titulada: Cartografando Experiências no Ensino de História: A Mídia Cinemática como fonte educativa em sala de aula. A mesma teve como problemática, compreender quais as concepções sobre mídias cinemáticas e o seu papel no ensino, são percebidas nos trabalhos realizados por professores no ensino de História na cidade do Rio Grande/RS, Brasil. O material empírico foi pautado em questionários semiestruturados respondidos por vinte e seis professores da rede básica de ensino e, também, por narrativas orais. A fundamentação teórica está ancorada em autores como Ferro (2010), Carmo (2012) e Fonseca (2012) para o qual a utilização destes "produtos culturais" na sala de aula podem levar o estudante a se envolver mais com as aprendizagens, mediante processos investigativos e "mais vivos". Desta forma, constatamos que o cinema como mobilizador de aprendizagens, favorece um espaço propício para discussão e construção de novos conhecimentos, mediante a reflexão, a curiosidade e a criticidade dos estudantes.
\end{abstract}

Palavras-chave: Mídia cinemática. Professores de história. Ensino de História.

\begin{abstract}
The present work aims to present some exploratory notes about the master's dissertation entitled: Mapping experiences in the teaching of History: Cinematic Media as an educational source in the classroom. It has as a problem, to understand which conceptions about kinematic media and their role in teaching are perceived in the works carried out by teachers in teaching of History in the city of Rio Grande / RS, Brazil. The empirical material was based on semi-structured questionnaires answered by twenty-six teachers of the basic education network and also by oral narratives. The theoretical foundation is anchored in authors such as Ferro (2010), Carmo (2012) and Fonseca (2012), for whom the use of these "cultural products" in the classroom can lead the student to become more involved with the learning process investigative and "more alive". In this way, we find that cinema as a mobilizer of learning, favors a space conducive to discussion and construction of new knowledge, through reflection, curiosity and criticality of students.
\end{abstract}

Keywords: Cinematic media. History teachers; History Teaching.

1 Professor da Rede Estadual de Ensino do Estado do Rio Grande do Sul. Doutorando em História pelo Programa de Pós-Graduação em História da Universidade Federal de Pelotas - UFPEL. Mestre em Educação, Licenciado e Bacharel em História pela Universidade Federal do Rio Contato: luizsoaresrg@gmail.com 


\section{Considerações iniciais}

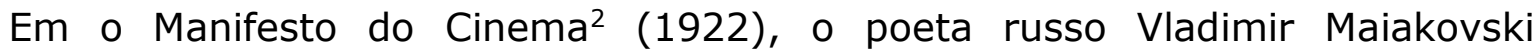
escreveu sobre o cinema ser considerado por muitos um espetáculo; e como todo espetáculo, necessita de telespectadores para que possa ser compartilhado sentimentos distintos, desde anseios e alegrias contidas no filme até o mais traumático dano que possa ser veiculado em uma mídia, trazendo sofrimento aos personagens e aflição a quem os assiste. O autor aponta ainda que o cinema é uma concepção de mundo, sendo o princípio das ideias, um veículo em movimento, enfim, um verdadeiro esporte. Refletindo sobre o Manifesto do Cinema, escrito por Maiakowisk, concordamos quando ele pondera o caráter de entretenimento, no entanto, tecemos algumas considerações sobre o produto cultural e sua utilização no ensino para muito além disso.

Começamos por atentar que o presente artigo é um recorte da investigação de mestrado em Educação e tem por intuito tecer algumas considerações sobre a investigação titulada: Cartografando Experiências no Ensino de História: A Mídia Cinemática como fonte educativa em sala de aula, desenvolvida no Mestrado Acadêmico em Educação do Programa de Pós-Graduação em Educação da Universidade Federal do Rio Grande - FURG.

Cabe ressaltar que na investigação buscamos responder quais concepções sobre mídias cinemáticas e seu papel no ensino eram percebidas nos trabalhos realizados por professores no ensino de História na cidade do Rio Grande/RS. Neste sentido, recortes da pesquisa foram realizados com a finalidade de analisarmos com mais afinco os dados obtidos. E ratificamos, amparados no referencial teórico levantado, que utilizar o cinema como um "produto cultural" (CARMO, 2012; FERRO, 2010; FONSECA, 2012) propicia aos estudantes uma variedade de possibilidades de (re)construção de conhecimentos históricos que podem ser problematizadas, discutidas em sala de aula ampliando os horizontes de análise deste material e suas relações com o tempo e os contextos dos estudantes.

2 O Manifesto do Cinema é um artigo publicado no número 5 - de 12 de outubro de 1922, na revista Kino-fot de Moscou/Rússia. Disponível em: Albera (2002). 
A justificativa para a realização desta pesquisa centra-se no fato de que as mídias cinemáticas são "produtos culturais" (CARMO, 2012; FERRO, 2010; FONSECA, 2012) de grande valia para o uso em sala de aula, dependendo do viés norteador do professor em relação à mesma, visto que os filmes proporcionam um espaço para realização de debates, ampliando o processo de ensino-aprendizagem, tornando-o significativo para os estudantes e professores.

Este artigo, em específico, tem como objetivo apresentar algumas notas sobre as descobertas encontradas durante a realização da pesquisa, considerando, sobretudo, apontamentos realizados por professores na primeira parte da investigação, durante o ano de 2014, e que foi organizado em três partes. A primeira depara sobre o referencial teórico e alguns conceitos utilizados, a segunda dispõe sobre a metodologia e a terceira apresenta alguns resultados das análises da pesquisa e por último uma breve conclusão sobre os apontamentos encontrados durante a realização da investigação com alguns professores da rede básica de ensino da cidade do Rio Grande/RS.

\section{Referenciais e alguns conceitos e princípios}

Podemos dizer que nos deparamos com uma bibliografia vasta e consistente sobre o tema, mas escolhemos como suporte alguns autores que, em seus estudos, problematizam, tensionam e refletem sobre as "mídias cinemáticas"3 e na sua significação junto à escola e, em especial, no ensino de História. Marcelo Cousin, por exemplo, em seus estudos afirma que as películas envolvem uma gama de informações que podem ser problematizadas pelo professor, e este possui a tarefa de articular as discussões através dos (múltiplos) significados do filme com o conteúdo e os conceitos em sala de aula (COUSIN, 2012).

Sabe-se que as mídias cinemáticas estão cada vez mais presentes no cotidiano das pessoas, cuja exibição foi facilitada pelos extintos videocassetes e suas mídias

\footnotetext{
3 Por mídia cinemática entendemos toda e qualquer imagem em movimento, isto é, longas e curta-
} metragens. 
VHS e, atualmente, seja através do DVD (Digital Versatile Disc, tradução para o português, Disco Digital Versátil), da mídia BluRay (mídia de alta definição), através das telas de cinema com qualidade Imax (com resolução 4k) e/ou ainda por meio de serviços de streamings. O cinema, no decorrer dos anos, se aperfeiçoou, difundindose para a sociedade, alcançando um número extraordinário de pessoas que possuem alguns dos aparelhos citados em suas residências. Isso ocorreu não só pelo avanço da tecnologia, mas, também, pelo barateamento e acessibilidade com o passar do tempo.

As mídias cinemáticas também são consideradas produtos didáticopedagógicos, que podem auxiliar o professor a elucidar os conteúdos, reforçando, facilitando e/ou contribuindo para as aprendizagens e a formação crítica dos estudantes, além do aperfeiçoamento da arte da/na docência. Esta dimensão da arte implica o imbricamento de uma estética do sensível no exercício docente junto a uma epistemologia da formação. Nessa perspectiva, Benjamim (1994), destaca a importância que a imagem em movimento exerce sobre o público que o vê, através da linguagem cinematográfica, com suas significações culturais, sociais, estéticas e outras. O mesmo considera ainda o caráter sensível do cinema, sendo eleito por ele, como a arte primeira, no que tange a percepção, as significações que a arte cinemática exerce nos atores sociais na contemporaneidade divertindo e alargando a percepção humana.

Nesta direção, alguns objetivos nortearam o desenvolvimento da pesquisa, como por exemplo, compreender que concepções sobre as mídias cinemáticas fundamentam as experiências educativas dos professores de História do grupo investigado. A identificação dos objetivos traçados pelos professores participantes da pesquisa quando se propõem a utilizar estas mídias no ensino de História.

O referencial teórico está ancorado principalmente nos escritos dos historiadores Marc Ferro (2010) e Barros (2012), sobre cinema e História e suas possibilidades de análise não apenas do período que se tentou retratar, mas também do período em que as obras cinematográficas foram produzidas; Duarte (2002), Carmo (2012) e Fonseca (2012), sobre a relação História, cinema e educação e suas múltiplas possibilidades de utilização em sala de aula. Nos escritos do filósofo Walter 
Benjamim (1994), que suscita reflexões sobre as significações culturais, sociais e estéticas das obras cinematográficas e do sociólogo John B. Thompson (2011), que pondera sobre a ideologia e cultura moderna através dos meios de comunicação cultural em massa, como de fato é o cinema e as influências que este artefato fílmico provoca nos telespectadores.

Sabemos que a utilização das mídias cinemáticas no ensino não se configura como uma tarefa nova no cotidiano do professorado no Brasil. Durante o segundo decênio do século XX, o pedagogo Jonathas Serrano, na obra Metodologia da História na aula primária (1917) já apontava para os benefícios que os filmes proporcionariam para o ensino de História. Além disto, Serrano (1917), defendia a utilização do cinema a serviço da História, assegurando a veracidade dos fatos históricos. Assim como Serrano, o geógrafo Carlos Delgado de Carvalho, em 1957, no livro Introdução metodológica aos Estudos Sociais, também informava sobre os benefícios da utilização do cinema em prol de um ensino mais significativo aos estudantes, senso assim, o cinema é considerado um significativo veículo midiático, representativo e que poderia ser utilizado.

Para o sociólogo norte-americano John Thompson (2009), o telespectador interage com a mensagem que está sendo veiculada na mídia, proporcionando a interação com o conhecimento, seja ele histórico ou não. Nesta perspectiva, percebemos aqui um ponto importante a ser observado: a questão da aprendizagem pública, isto quer dizer que a todo momento e em qualquer lugar estamos aprendendo História, conforme os ensinamentos de Peter Lee (2006).

No decorrer do século XX e XXI, outros estudiosos também afirmaram sobre a importância deste produto cultural para a educação, ampliando as discussões sobre o seu papel. Segundo Oliveira, Almeida e Fonseca (2012, p. 31), "vários historiadores e estudiosos da Educação pensam e produzem conhecimento a respeito das possibilidades das relações entre cinema e história". No entanto, os elementos visuais, inclusive os presentes nas mídias cinemáticas, não eram considerados por muitos historiadores como uma fonte para o estudo e ensino da História. Em 1998, os Parâmetros Curriculares Nacionais (PCNs), de História confirmaram o cinema um meio fundamental como fonte de informação passível de ser interpretada, analisada 
e comparada. Neste sentido, o documento do Ministério da Educação ressalva que:

No caso de trabalho didático com filmes que abordam temas históricos é comum a preocupação do professor em verificar se a reconstituição das vestimentas é ou não precisa, se os cenários são ou não fiéis, se os diálogos são ou não autênticos. Um filme abordando temas históricos ou de ficção pode ser trabalhado como documento, se o professor tiver a consciência de que as informações extraídas estão mais diretamente ligadas à época em que a película foi produzida do que à época que retrata. É preciso antes de tudo ter em mente que a fita está impregnada de valores, compreensões, visões de mundo, tentativas de explicação, de reconstituição, de recriação, de criação livre e artística, de inserção de cenários históricos construídos intencionalmente ou não por seus autores, diretores, produtores, pesquisadores, cenógrafos etc. (BRASIL, 1998, p. 88).

Os PCNs reconhecem que os filmes são elaborações artísticas que podem servir como documento, porém temos que considerar que estão investidos de "valores, compreensões, visões de mundo" etc., ligados a sua produção e a quem os produz.

Ao refletirmos sobre as prerrogativas dispostas nos Parâmetros Curriculares sobre a utilização de filmes no ensino, constatamos que estudar a História através das mídias cinemáticas faz com que compreendamos que todos os elementos estão vinculados a um contexto. E este contexto cinematográfico precisa ser analisado, pois muitas vezes ele veicula mais aspectos ideológicos de quem o produz e da sociedade em que foi produzido, do que propriamente do que se tentou representar.

Duarte (2002), amparada em Bourdieu, expõe que a experiência dos grupos sociais com o filme "contribui para desenvolver o que se pode chamar de 'competência para ver', isto é, certa disposição, valorizada socialmente, para analisar, compreender e apreciar qualquer história contada em linguagem cinematográfica", proporcionando um cinema educacional e libertador para os grupos consumidores das mídias cinematográficas (BOURDIEU apud DUARTE, 2002, p. 13). Desta forma, o filme bem como outras representações audiovisuais - como curtas metragens, animações entre outras podem tornar o ensino de História estimulante, e 
é provável que boa parte dos historiadores, que atuam na educação, sabem da importância exercida por este artefato no processo de ensino e aprendizagem.

Barros (2012) e Ferro (2010) também afirmam que o cinema pode e deve ser utilizado como recurso para o ensino. Barros expressa que a utilização deste material em sala de aula aumenta as potencialidades de se aprender o conteúdo histórico auxiliando o professor nos procedimentos teóricos e metodológicos, no que se refere, ao ensino da História. O filme, considerado por muitos teóricos como a sétima arte, acaba por instigar cada indivíduo que a assiste, despertando os seus sentidos e ampliando seus horizontes. Por sua vez, Marc Ferro foi o historiador que deu início aos estudos sobre o cinema na História no âmbito da corrente teórica da Escola dos Annales. A contribuição de seus estudos para a área e o ensino foi diversa, uma vez compreender que através deste artefato audiovisual é possível "analisar [...] principalmente a narrativa, o cenário, o texto, as relações do filme com o que não é filme: o autor, a produção, o público, a crítica, o regime" (FERRO, 2010, p. 203). O autor apresenta ainda que a utilização do cinema na história pode ser vista de duas maneiras: a primeira como sendo um testemunho do presente e a segunda como um discurso do passado. Enfim, todo um contexto poderá ser analisado, o que também irá acarretar uma apreensão da sociedade que o representa.

$\mathrm{Na}$ perspectiva de Ferro, o cinema incorpora diversas assimetrias, interesses e ideários como qualquer produção cultural:

Assim como todo produto cultural, toda ação política, toda indústria, todo filme tem uma história que é História, com sua rede de relações pessoais, seu estatuto de objetos e dos homens, onde privilégios e trabalhos pesados, hierarquias e honras encontram-se regulamentados, os lucros da glória e os do dinheiro são aqui regulamentados com a precisão que seguem os ritos de uma carta feudal: guerra ou guerrilha entre atores, diretores, técnicos, produtores que é mais cruel à medida que, sob o estandarte da Arte, da Liberdade, e na promiscuidade de uma aventura comum, não existe empreendimento industrial, militar, político ou religioso que conheça a diferença tão intolerável entre o brilho e a fortuna de uns e a obscura miséria dos outros artesãos da obra. (FERRO, 2010, p. 19).

Há, portanto, na produção de um filme uma "disputa" que expõe vicissitudes inerentes aos atores sociais que o produzem. Em outra passagem, Ferro (2010, p. 
33) nos recomenda "analisar no filme tanto a narrativa quanto o cenário, a escritura, as relações do filme com aquilo que não é filme: o autor, a produção, o público, a crítica, o regime de governo", ou seja, há um "filme" atrás/através do filme que também necessita ser avaliado. Sobre a afirmativa do autor, podemos constatar que o cinema pode promover uma análise através de seus simbolismos, pressupondo em uma desconstrução analítica do material veiculado na mídia. E continua:

Não é suficiente constatar que o cinema fascina, que inquieta; eles se apercebem que, mesmo fiscalizado, um filme testemunha. Termina por desestruturar o que várias gerações de homens de Estado, de pensadores, de juristas, de dirigentes ou de professores tinham reunido para ordenar num belo edifício. Destrói a imagem do duplo que cada instituição, cada indivíduo se tinha constituído diante da sociedade. A câmera revela o funcionamento real daquela, diz mais sobre cada um do que queira mostrar. Ela descobre o segredo, ela ilude os feiticeiros, tira as máscaras, mostram o inverso de uma sociedade, seus lapsos. É mais do que preciso para que, após a hora do desprezo venha à desconfiança, a do temor. A imagem, as imagens sonoras, esse produto da natureza, não poderiam ter, como o selvagem, nem língua nem linguagem. A idéia de um gesto poderia ser uma frase, esse olhar, um longo discurso é totalmente insuportável: significaria que imagem, as imagens [...] constituem a matéria de outra história que não a História, uma contra-análise da sociedade. (FERRO, 1974, p. 202-203).

O excerto acima direciona o trabalho com as mídias cinemáticas na História, denotando uma análise da sociedade e as tensões em que o mesmo foi produzido. Para Eduardo Morettin, que analisou o lugar ocupado pelo cinema na História na obra de Ferro, "o filme atinge as estruturas da sociedade e, ao mesmo tempo, age como um 'contra-poder' por ser autônomo em relação aos diversos poderes desta sociedade" (MORETTIN, 2003, p. 14).

Para o autor é necessário se valer de todos os aspectos que o filme proporciona para prosseguir no ato de analise que a obra cinematográfica procurou significar, buscando um exame oriundo da própria análise do material cinematográfico. Nesse interím, Morettin se vale dos escritos de Leutrat (1995) sobre esse exame minucioso do cinema, em que é preciso

[...] delimitar um terreno, medi-lo, esquadrinhá-lo muito precisamente (trata-se de um fragmento de obra ou de uma obra inteira). Uma vez 
recortado e batizado o terreno, devemos nele, e em conformidade com a sua natureza, efetuar seus próprios movimentos de pensamento. Para este périplo é imperativo dispor de várias cartas, ou seja, de instrumentos trazidos de disciplinas diversas, para que se possa superpô-las, saltar de uma a outra, estabelecer as passagens, as trocas e as transposições [...]. A descoberta de tais signos depende das questões postas às obras, cada obra necessitando de questões particulares. Como diz Gérard Granel, 'não há migalhas numa obra, nem 'triagem' possível entre o que seria importante, revelador ou insignificante'. [...] Afinal de contas, tudo pode ser levado em conta, dado que é disto que o sentido advém. (LEUTRAT, 1995, p. 32).

O excerto evidencia a necessidade de aceitar todo e qualquer detalhe da obra cinematográfica, mesmo que esses detalhes sejam irrelevantes, insignificantes para a análise. De acordo com Morettin (2003, p. 39), "não isolamos a obra de seu contexto, pois partimos das perguntas postas pela obra para interrogá-lo".

Em direção semelhante, Fonseca (2012), corrobora com este pensamento ao firmar que a mídia cinemática também é persuasiva e atua subjetivamente, pois

[...] distrai, fascina, inquieta, seduz, comove, inspira, provoca diversas sensações: medo, alegria, tristeza; alimenta a imaginação, os sonhos; amplia o modo de ver, sentir e compreender as pessoas e o mundo. Com o avanço das novas tecnologias, desenvolveu-se de forma rápida e sofisticada, tornando-se uma poderosa indústria, capaz de mobilizar milhões de espectadores, consumidores culturais, em diferentes lugares do planeta. Logo, o cinema detém um enorme poder de produção, de difusão de valores, ideias, padrões de comportamento e consumo, modos de leitura e compreensão do mundo. (FONSECA, 2012, p. 260).

De acordo com este ponto de vista, a fonte fílmica, deve ser compreendida criticamente, posto não admitir neutralidade naquilo que veicula, mas permite ampliar os horizontes quando utilizada em sala de aula, relacionando-a com os conteúdos históricos e sendo devidamente problematizada, além de suscitar emoções e sentimentos.

Ainda na perspectiva do ensino, Fonseca assevera que

[...] ensinar é estabelecer relações interativas que possibilitem ao educando elaborar representações pessoais sobre os conhecimentos, os objetos de ensino e da aprendizagem. O ensino se articula em torno dos alunos e dos conhecimentos e a aprendizagem depende desse conjunto de interações. (FONSECA, 2012, p. 166). 
Seguindo o raciocínio da autora, estas mídias são de extrema importância, pois abrangem temas que podem ser abarcados em sala de aula, através de dinâmicas didáticas pedagógicas interativas que envolvam a imagem, o som, a fotografia, desde que tenham relação com a película escolhida e com o conteúdo ao qual pretende-se trabalhar. Isto poderá contemplar as inquietações dos discentes de acordo com o trabalho docente que está sendo desenvolvido no momento, e cabe ao professor conduzir a mesma de forma que consiga atingir os objetivos traçados para a atividade educativa.

\section{Breve consideração sobre a metodologia}

O aporte metodológico da pesquisa está amparado na análise de conteúdo proposto pela pesquisadora Laurence Bardin (2012). Este método, segundo a autora, tem por intuito a descrição, inferência e interpretação dos materiais coletados e catalogados. Consiste num conjunto de técnicas e instrumentos metodológicos capazes de efetuar a exploração objetiva de dados, informações e/ou discursos, fazendo-os aparecer no conteúdo das diversas categorias de documentos. Para realizar a análise de conteúdo, utilizou-se como um dos instrumentos de coleta de dados questionários estruturados (entregues a trinta e três professores da rede pública da cidade, dos quais retornaram vinte e seis). Além desta, pretendíamos utilizar o Grupo Focal ${ }^{4}$ como auxiliar no processo de coleta de dados. No entanto, durante o desenvolvimento da segunda parte da investigação, em função de incompatibilidade de horários dos participantes da pesquisa e impossibilidade de agregar esses sujeitos em grupo, foi necessário alterar o processo. Diante do impasse frente ao método escolhido para auxiliar no levantamento da empiria da investigação, optamos por trabalhar com entrevistas individuais e, para tal, utilizamos como teórica da área de entrevista oral Heloísa Szymanski. Foram realizadas cinco entrevistas com professores que compõem a base dos sujeitos investigados com o intuito de aprofundar as discussões sobre as categorias que

4 Segundo Lervolino e Peliccone (2001), o Grupo Focal é uma técnica de pesquisa qualitativa que objetiva coletar dados em grupo para inferir se opiniões, anseios, sentimentos etc. 
surgiram na decorrência da análise dos questionários.

No que diz respeito aos questionários semiestruturados foram aplicados no ano de 2014, junto a vinte e seis professores respondentes da rede estadual e municipal de ensino do município de Rio Grande, localizado no estado do Rio Grande do Sul, Brasil, e já foram analisados anteriormente. Algumas categorias decorrentes deste material emergiram como o gênero fílmico de preferência, as abordagens metodológicas principais, as obras cinematográficas mais utilizadas, a frequência das mídias cinemáticas em sala de aula, a rede institucional de ensino em que se realiza e a relação entre tempo na profissão e formação com o tipo de utilização dos filmes.

Além disto, percebemos algumas peculiaridades no trato da mídia pelos professores que estão sendo ponderados como: a apresentação do filme através de um roteiro pré-estabelecido, elaboração de resumos, busca por informações adicionais sobre a mídia cinemática, análise sobre a relação entre conteúdo e produção fílmica, as plenárias de discussão, os questionamentos objetivos e subjetivos sobre a película que estabeleçam pontes com o conteúdo desenvolvido, além de outros aspectos que estão sendo levantados durante a realização das entrevistas com os respectivos professores participantes da investigação.

\section{3. $O$ estudo e alguns resultados}

Nesta seção apresentaremos algumas descobertas decorrentes das análises realizadas, sobretudo mediante aos questionários. A primeira delas diz respeito à frequência da utilização das mídias cinemáticas em sala de aula pelos professores participantes da pesquisa.

No estudo junto aos professores levantou-se que a maioria faz uso de filmes na sala de aula, pois cerca de 30\% declararam utilizar algumas vezes por mês e somente 4\% assumiram não fazer uso desta mídia em seus processos de ensino e aprendizagem. O gráfico a seguir apresenta a frequência da utilização pelos professores.

Gráfico 1 - Frequência da utilização de filmes nas aulas de História 


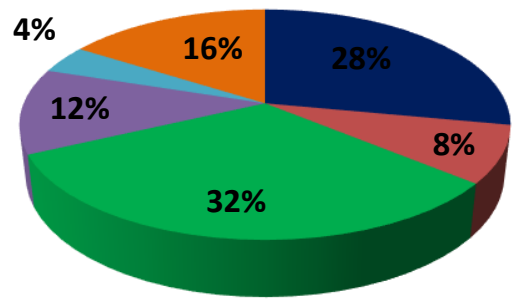

- Algumas vezes por mês

- Depende do Conteúdo

- Uma vez por trimestre

- Raramente

- Não utilizo

Outros

FONTE: Elaborado pelo autor.

Os dados do gráfico acima demonstram que $32 \%$ dos pesquisados utilizam a mídia cinemática pelo menos uma vez por trimestre para discutir os temas abordados em aula. Já $28 \%$ dos pesquisados, utilizam algumas vezes por mês e $16 \%$ relataram que utilizam de duas a três vezes durante ano, seguidos por $12 \%$ que raramente utilizam e $8 \%$ que depende do conteúdo que está sendo desenvolvido em sala de aula. Um dado interessante que foi observado nos questionários é que apenas 4\% dos professores, que corresponde a um professor, apontou que não utiliza filmes em sala de aula por compreender que o uso desses "produtos culturais" em sala de aula é "perda de tempo", e pudemos perceber que na concepção deste, ao trabalhar um filme em sala de aula, estaria perdendo tempo para explanar os conteúdos relativos a História. Percebemos, assim, que os professores em sua grande maioria utilizam filmes para trabalhar os conteúdos e/ou temas relativos à História em sala de aula.

No que tange a indumentária histórica e outros detalhes da narrativa fílmica, foi possível verificar através dos questionários, que $50 \%$ dos professores pesquisados ao trabalharem com filmes em sala de aula, propiciam aos estudantes as possibilidades de analisarem estes aspectos considerando a temporalidade e a evolução destes através do tempo. Nesse sentido, esses aspectos relativos à obra fílmica, são pontos explorados pelos professores contextualizando os conteúdos relativos ao filme e situando os estudantes na História.

Sobre isso, Thompson assevera que,

[...] Os personagens que se apresentam nos filmes e nos programas de televisão tornam-se referências comuns para milhões de indivíduos 
que podem nunca interagir um com o outro, mas que partilham, em função de sua participação numa cultura mediada, de uma experiência comum e de uma memória coletiva. (THOMPSON, 2009, p. 219).

A partir dessa premissa, os sentimentos comuns de muitas pessoas em relação a personagens de novelas, filmes, seriados ou a celebridades, cujas vidas parecem bem próximas das suas suscitando a impressão de conhecê-las. Apesar disso, tais atitudes e sentimentos remetem uma busca por aproximações com base nas personificações demonstradas na obra fílmica (COUSIN, 2012) em que o pertencimento e a identidade das personagens através dos modos de ver, pensar e agir são incorporadas pelo público.

E Thompson complementa ainda, afirmando que,

[...] As formas simbólicas são fenômenos sociais: uma forma simbólica que é recebida apenas pelo próprio individuo [...] A troca de formas simbólicas entre produtores e receptores implica, em geral, uma série de características que podemos analisar sob o título de transmissão cultural. (THOMPSON, 2011, p. 221).

Diante disto, o filme se torna uma forma de "troca simbólica" em sala de aula, devido os diálogos e as representações contidas no mesmo que acabam por interagir com o público, daí a ideia da "transmissão cultural". Cabe ressaltar que todo e qualquer filme, independente se é um curta, longa metragem, animação ou ficção, todas fazem parte da vida das pessoas, assim como as mídias que os veicula. Dentro desta concepção, Thompson (2009) afirma que:

[...] O papel das instituições da mídia é tão fundamental, e seus produtos se constituem em traços tão onipresentes da vida cotidiana, que é difícil, hoje, imaginar o que seria viver num mundo sem livros e jornais, sem rádio e televisão e sem os inúmeros outros meios através dos quais as formas simbólicas são rotineira e continuamente apresentadas a nós [...] (THOMPSON, 2009, p. 129).

Thompson expõe que as instituições midiáticas estão presentes, mais do que isso, são "onipresentes" na vida dos grupos sociais na atualidade, que as mesmas possibilitam o diálogo, a comunicação, as discussões sobre o que é veiculado nestes materiais. Nesse sentido, o cinema que também é artefato contemporâneo para o 
ensino de História, com vistas à promoção da reflexão através da sétima arte é permanentemente propalado por mídias diversas. Isto implica em compreender o sistema signo - são códigos que constituem todo sistema de comunicação visual, verbal e não verbal, permitindo a troca de saberes e informações. Cada código possui significados que são estabelecidos nas relações existentes entre significante e significado e que compõe toda a obra cinematográfica.

Um dado interessante que constatamos durante as análises dos questionários referem-se à finalidade colocada pelos professores que os impulsionaram a utilizarem as mídias cinemáticas em sala de aula. Entre todos os pesquisados, ficou claro que há certo consenso quanto à finalidade da utilização de filmes em aula, ou seja, como apoio para discussões e significação dos conteúdos. Dos vinte e seis (26) professores pesquisados, vinte e um (21) marcaram ambas as respostas como motivação principal para utilizar as mídias cinemáticas em sala de aula totalizando mais de $80,7 \%$ do grupo.

No entanto, os participantes marcaram múltiplas opções, como a utilização de filmes para a preparação de um novo tema ou conceito a ser trabalhado, por exemplo, que aparece nas respostas de doze (12) professores. Já dezessete (17) professores marcaram a opção ilustração de temas como um dos motivos para utilizar a mídia cinemática para trabalhar os conteúdos históricos. E por último, onze (11) professores, que corresponde a $44 \%$ do total, utilizam como forma a desenvolver conceitos relativos à ciência da história, enquanto quinze (15) ou 56\% preferem este "produto cultural" (CARMO, 2012; FERRO, 2010), para aproximarem o conteúdo a realidade do aluno, além de outros, como, por exemplo, a avaliação de fontes históricas. Como podemos perceber no quadro abaixo:

Quadro 1 - Finalidade da Mídia Cinemática nas aulas de História segundo os professores pesquisados

\begin{tabular}{|l|c|}
\hline \multicolumn{1}{|c|}{ Finalidade/Objetivo } & $\begin{array}{c}\text { No de } \\
\text { vezes }\end{array}$ \\
\hline Apoio para discussões sobre o conteúdo & 21 \\
\hline Aproximar o conteúdo da realidade dos estudantes & 15 \\
\hline Desenvolver conceitos & 11 \\
\hline Ilustração de temas & 17 \\
\hline Iniciar novos conteúdos & 12 \\
\hline
\end{tabular}




\begin{tabular}{|l|l|}
\hline Significação do conteúdo & 21 \\
\hline Outros: Avaliação de Fontes Históricas & 01 \\
\hline Outros: Não Utilizo & 01 \\
\hline
\end{tabular}

Fonte: Elaborado pelo autor.

O terceiro destaque refere-se às obras mais utilizadas pelos professores, segundo suas afirmativas. Ao analisar as obras cinematográficas ${ }^{5}$ apontadas pelos professores pesquisados constatam-se uma variedade de películas utilizadas pelos mesmos para desenvolverem suas aulas. Ao todo foram mencionados quarenta e quatro (44) filmes. Estes têm várias intencionalidades: de modo a iniciar um novo conteúdo, para finalizar o tema trabalhado ou, simplesmente, para ilustrar, visualmente, o que está sendo discutido em sala de aula, entre outros exemplos. Nos apontamentos dos professores é possível perceber ainda que os títulos fílmicos selecionados são obras cinematográficas que retratam ou tentam retratar fatos de grande comoção e que marcaram a história conhecida, como por exemplo, a ascensão do nazismo, a segunda Guerra Mundial e a Revolução Industrial - sendo considerada um marco no processo de fabricação em larga escala e que alterou o modo de produção, dando início ao capitalismo moderno.

No quadro a seguir, é possível verificar os títulos que foram mencionados mais de uma vez pelos vinte e seis (26) professores ao responderem o questionário.

Quadro 2 - Títulos fílmicos mais elencados pelos professores participantes da pesquisa

\begin{tabular}{|c|c|c|}
\hline TÍtULOS FÍlMICOS & TEMAS ABORDADOS & No VEZES CITADOS \\
\hline O Menino do Pijama Listrado & $\begin{array}{c}\text { Segunda Guerra Mundial; } \\
\text { Holocausto; Campos de } \\
\text { Concentração }\end{array}$ & 7 \\
\hline A Guerra do Fogo & $\begin{array}{c}\text { Descoberta do fogo; } \\
\text { Tecnologia }\end{array}$ & 2 \\
\hline Gladiador & O Império Romano & 2 \\
\hline A Menina que Roubava Livros & Nazismo & 2 \\
\hline Tempos Modernos & Revolução Industrial \\
Olga & $\begin{array}{c}\text { Governo Vargas; Intentona } \\
\text { Comunista; Nazismo }\end{array}$ \\
\hline
\end{tabular}

5 Os dados referentes às obras cinematográficas foram obtidos junto ao questionário entregue aos professores que concordaram em participar da pesquisa. 
Fonte: Elaborado pelo autor.

A maioria dos filmes relacionam-se com a História geral e apenas um deles inclui também a história do Brasil. O que denota um interesse maior por parte dos pesquisados em utilizarem filmes que retratem acontecimentos memoráveis da História mundial, como, por exemplo, a Segunda Guerra Mundial, a descoberta do fogo, a revolução industrial e o Império Romano. No que tange a História do Brasil, apenas o filme Olga foi pontuado por dois professores do total. Nesse sentido, levantamos algumas hipóteses sobre a não utilização de filmes sobre a História do Brasil em sala de aula. Em primeiro lugar, podemos dizer que os professores podem desconhecer títulos e a produção cinematográfica brasileira que contemplem a História de nosso país. Em um segundo momento, podemos pensar que o Brasil, embora presente em uma extensa lista de filmes nacionais e, inclusive, internacionais, é apresentado, muitas vezes, de forma estereotipada o que pode gerar descredibilidade entre os professores. E, como terceira probabilidade há que se considerar certa "colonialidade" 6 nos currículos que tendem a enfatizar a história geral em detrimento do país, de sua gente, de suas lutas, contradições e potencialidades.

Fica claro, segundo as fontes teóricas que fundamentam esta pesquisa e pelos sujeitos de pesquisa, que é valiosíssima a utilização das mídias cinemáticas em sala de aula, uma vez que as mesmas proporcionam aos estudantes uma interação epistemológica, cultural, política, estética, sensível e emocional. Um dos professores pesquisados, por exemplo, ponderou que

[...] o filme deve ser visto como uma expressão artística e enquanto tal pode e deve ser tratado como uma ferramenta eficaz para a reflexão sobre a vida, sobre nossa formação de identidade e na capacidade de criticidade humana. [...] os filmes auxiliam na aprendizagem dos alunos, pois eles aprendem mais com a linguagem imagética, do que com a exposição de conteúdo apenas (Professora da Escola Estadual Carlos Loréa Pinto).

6 Versão unilateral da história e da ciência relacionada aos grupos que as produzem, decorrentes dos processos de colonização. Produtora de uma "história única", aquela que se oficializa, banaliza e naturaliza, sem que os silenciosos/silenciados tenham oportunidade de oferecer outras narrativas. 
Neste caso a professora concebe a mídia cinemática como arte e ciência, destacando-a como linguagem imagética que gera aprendizagens.

Além desta função, por envolver diversos mecanismos na produção de um filme - cenários, personagens, enredo, trilha sonora, fotografia, pode promover a elucidação e a compreensão de determinados conteúdos históricos. Esta abordagem acaba tornando o ensino-aprendizagem dos estudantes mais significativo, mais prazeroso, e pode aguçar a consciência crítica em cada um deles. Um exemplo sobre isso é destacado pela professora da Escola Municipal Altamir de Lacerda. A mesma aponta que ao trabalhar com filmes em sala de aula, os estudantes sentem-se mais à vontade para debaterem e conseguem realizar associações entre passado e presente, o que nas palavras da própria pesquisada "é um estudo significativo, uma vez que eles conseguem compreender o processo, e compreendendo o processo, o senso crítico dos alunos é ampliado" (Professora da Escola Municipal Altamir de Lacerda). Constatamos através das palavras escritas da professora que o cinema é uma fonte que desperta a curiosidade, a criticidade de maneira significativa como foi mencionado anteriormente.

\section{Algumas considerações}

No que tange a utilização das mídias cinemáticas em sala de aula pelos professores, quase cem $100 \%$ afirmaram fazer uso da mesma e percebemos que a utilização deste artefato é considerada valiosa quando utilizada com propósitos definidos pelo professor. Um dos aspectos que merece destaque neste trabalho refere-se a sua finalidade de utilização, sendo unânime a intenção em proporcionar aos estudantes uma significação do conteúdo através da estimulação, da reflexão e socialização entre os colegas dentro da sala de aula. Além disso, constatamos que as mídias cinemáticas para os investigados, envolvem diversos elementos que necessitam ser explorados e discutidos desde a produção, passando pelo cenário, enredo, pelos personagens, pela trilha sonora, pelas imagens em movimento, enfim, todo processo que compõe a obra fílmica que desdobra na compreensão de determinados temas. Segundo os professores a abordagem da história pelo cinema 
em sala de aula acaba tornando a aprendizagem dos estudantes significativa, prazerosa e, conforme destacou Carmo (2012), tem a função de expandir os horizontes dos alunos também.

Frisamos que cabe ao professor promover um espaço de discussão num processo de planejamento didático pedagógico, pois a mídia cinemática sozinha não o fará e os discentes, provavelmente, também não o farão, pois precisam de um mediador qualificado nesta empreitada - e este mediador será o professor.

Concordamos que todo e qualquer material audiovisual, no caso desta pesquisa sobre à mídia cinemática, deve ser problematizada, posto que, como foi analisado anteriormente, não são apenas recursos ou ferramentas, mas sim, um "produto cultural" conforme ressaltou Carmo (2003) e Ferro (2010), e necessitam ser relacionados com os conteúdos históricos e suas respectivas fontes. Não deve ser pensada somente como ilustração de temas, mas, sim, como plataforma para a problematização da História, utilizando todos os meios necessários e/ou disponíveis para a análise dos conteúdos/temas que estão sendo veiculados nos filmes. A mídia cinemática pode contribuir para o processo de ensino e aprendizagem de forma organizada visando ser significativa aos estudantes, elucidando os conteúdos históricos e, inclusive, gerando prováveis novas interpretações dos fatos.

Tendo em vista o recorte anunciado no início desta escrita, sobre as concepções dos professores sobre a mídia cinemática e seu papel no ensino de História na escola, podemos inferir que são diversificadas e, provavelmente, decorrentes de suas relações pessoais/particulares com a mídia, os processos formativos no qual estão e está imersos, as condições materiais que o espaço educativo oferece, além de outras como às relativas a cargas horárias ou jornadas de trabalho e do espaço-tempo da disciplina de História no currículo escolar.

Por fim, a investigação desenvolvida poderá contribuir para o aperfeiçoamento da formação do próprio investigador no que tange a utilização das mídias cinemáticas para trabalhar História em sala de aula, problematizando os significados que possuem e as metodologias adequadas quando o professor se dispõe a trabalhar os conteúdos históricos através do cinema. 


\section{Referências}

ALBERA, François. Eisenstein e o construtivismo russo. São Paulo: Cosac e Naify, 2002.

BARDIN, Laurence. Análise de conteúdo. Tradução Luís Antero Reto e Augusto Pinheiro. São Paulo: Edições 70, 2012.

BARROS, José D'Assunção. Cinema e história: entre expressões e representações. In: NÓVOA, Jorge; BARROS, José D'Assunção (org.) Cinema-história: teoria e representações sociais no cinema. Rio de Janeiro: Apicure, 2012. p. 9-52.

BENJAMIN, Walter. A obra de arte na era de sua reprodutibilidade técnica. In: BENJAMIN, Walter. Magia e técnica, arte e política: ensaios sobre literatura e história da cultura. São Paulo: Brasiliense, 1994. p. 165-196. (Obras escolhidas, v. 1).

BRASIL. Ministério da Educação. Secretaria de Educação Fundamental. Parâmetros curriculares nacionais: história. Brasília: MEC: SEF, 1998.

CARMO, Leonardo Cesar do. O cinema do feitiço contra o feiticeiro: cinema de massa e crítica da sociedade. Goiânia: Ed. da PUC Goiás, 2012.

CARVALHO, Carlos Delgado de. Introdução metodológica aos estudos sociais. Rio de Janeiro: Agir, 1957.

COUSIN, Marcelo. Janela para o mundo: o cinema como ponte entre lugares reais e imaginários. In: PORTUGAL, Jussara Fraga; CHAIGAR, Vânia Alves Martins (org.).

Cartografia, cinema, literatura e outras linguagens no ensino de geografia. Curitiba: Editora CRV, 2012. p. 65-77.

DUARTE, Rosália. Cinema e educação. 2. ed. Belo Horizonte: Autêntica, 2002.

FERRO, Marc. Cinema e história. Tradução Flávia Nascimento. São Paulo: Paz \& Terra, 2010.

FERRO, Marc. O filme: uma contra-análise da sociedade? In: LE GOFF, Jaques; NORA, Pierre. História: novos objetos. 2. ed. Rio de Janeiro: Francisco Alves, 1974, p. $199-215$.

FONSECA, Selva Guimarães. Didática e prática de ensino de história. Campinas: Papirus, 2012.

LEE, Peter. Em direção a um conceito de literacia histórica. Revista Educar, Curitiba, p. 131-150, 2006. Disponível em: http://revistas.ufpr.br/educar/article/view/5543/4057. Acesso em: 3 jan. 2021. 
LEUTRAT, Jean Louis. Uma relação de diversos andares: cinema \& história. Imagens: Cinema 100 anos, Campinas, n. 5, p. 28-33, 1995.

LERVOLINO, Solange Abrocesi; PELICIONI, Maria Cecilia Focesi. A utilização do grupo focal como metodologia qualitativa na promoção dasaúde. Revista da Escola de Enfermagem USP, v. 35, n. 2, p. 115-121, jun, 2001.

MAIAKOVSKI, Vladimir. O manifesto do cinema. Revista Kino-fot, Moscou, n. 5, out. 1922.

MORETTIN, Eduardo Victorio. O cinema como fonte histórica na obra de Marc Ferro. História: questões \& debates, Curitiba, v. 38, n. 1, jun. 2003. Disponível em: https://revistas.ufpr.br/historia/article/view/2713/2250. Acesso em: 3 jan. 2021.

OLIVEIRA Regina Soares de; ALMEIDA, Vanusia Lopes de; FONSECA, Vitória Azevedo da. História e cinema. In: CANO, Márcio Rogério de Oliveira (coord.). Coleção: a reflexão e a prática de ensino - história. São Paulo: Edigraf, 2012. v. 6, p. 31-45.

SERRANO, Jonathas. Metodologia da história na aula primária. Rio de Janeiro: Francisco Alves, 1917.

SZYMANSKI, Heloisa. Entrevista reflexiva: um olhar psicológico sobre a entrevista em pesquisa. In: SZYMANSKI, Heloisa (org.). A entrevista na pesquisa em educação: a prática reflexiva. Brasília: Plano Editora, 2002. p. 193-215.

THOMPSON, John Brookshire. Ideologia e cultura moderna: teoria social crítica na era dos meios de comunicação de massa. 9. ed. Petrópolis: Vozes, 2011.

THOMPSON, Jonh Brookshire. A mídia e a modernidade: uma teoria social da mídia. $11^{a}$ edição. Petrópolis, RJ, Vozes, 2009. 